Article

\title{
Speciation of Ruthenium(III) Chloro Complexes in Hydrochloric Acid Solutions and Their Extraction Characteristics with an Amide-Containing Amine Compound
}

\author{
Tomoya Suzuki ${ }^{1, *(1)}$, Takeshi Ogata ${ }^{1}$ (D), Mikiya Tanaka ${ }^{1}$, Tohru Kobayashi ${ }^{2}$, \\ Hideaki Shiwaku ${ }^{2}$, Tsuyoshi Yaita ${ }^{2}$ and Hirokazu Narita ${ }^{1}$ \\ 1 Environmental Management Research Institute, National Institute of Advanced Industrial Science and \\ Technology (AIST), 16-1 Onogawa, Tsukuba, Ibaraki 305-8569, Japan; t-ogata@aist.go.jp (T.O.); \\ mky-tanaka@aist.go.jp (M.T.); hirokazu-narita@aist.go.jp (H.N.) \\ 2 Materials Sciences Research Center, Japan Atomic Energy Agency (JAEA), 1-1-1 Koto, Sayo, Hyogo 679-5148, \\ Japan; tohru-k@spring8.or.jp (T.K.); shiwaku@spring8.or.jp (H.S.); yaita@spring8.or.jp (T.Y.) \\ * Correspondence: suzuki.tomoya@aist.go.jp; Tel.: +81-29-861-8260
}

Received: 29 June 2018; Accepted: 16 July 2018; Published: 20 July 2018

\begin{abstract}
The refining of platinum group metals is based mainly on solvent extraction methods, whereas $\mathrm{Ru}$ is selectively recovered by distillation as $\mathrm{RuO}_{4}$. Replacement of distillation by extraction is expected to simplify the purification process. To develop an effective extraction system for $\mathrm{Ru}$, we analyzed the $\mathrm{Ru}$ species in $\mathrm{HCl}$ with ultraviolet-visible (UV-Vis) and $\mathrm{Ru}$ K-edge extended X-ray absorption fine structure (EXAFS) spectroscopies, and we examined the properties of Ru extracted with $\mathrm{N}$-2-ethylhexyl-bis(N-di-2-ethylhexyl-ethylamide) amine (EHBAA) and trioctylamine (TOA). EXAFS and UV-Vis spectra of $\mathrm{Ru}$ in $\mathrm{HCl}$ solutions revealed that the predominant $\mathrm{Ru}$ species in $0.5-10 \mathrm{M} \mathrm{HCl}$ solutions changed from $\left[\mathrm{RuCl}_{4}\left(\mathrm{H}_{2} \mathrm{O}\right)_{2}\right]^{-}$to $\left[\mathrm{RuCl}_{6}\right]^{3-}$ with the $\mathrm{HCl}$ concentration. The extraction percentages $(E \%)$ of $\mathrm{Ru}$ in the EHBAA system increased with increasing $\mathrm{HCl}$ concentration, reached $80 \%$ at $[\mathrm{HCl}]=5 \mathrm{M}$, and decreased at higher $\mathrm{HCl}$ concentrations; the corresponding $E \%$ for TOA were low. EXAFS analysis of the extracted complex indicated that the $\mathrm{Ru}^{3+}$ had $5 \mathrm{Cl}^{-}$and $1 \mathrm{H}_{2} \mathrm{O}$ in its inner coordination sphere. The similarity of the dependence on $\mathrm{HCl}$ concentrations of the $E \%$ in the EHBAA system and the distribution profile of $\left[\mathrm{RuCl}_{5}\left(\mathrm{H}_{2} \mathrm{O}\right)\right]^{2-}$ on $\left[\mathrm{RuCl}_{n}\left(\mathrm{H}_{2} \mathrm{O}\right)_{6-n}\right]^{3-n}$ suggested that the EHBAA extracted the pentachlorido species.
\end{abstract}

Keywords: solvent extraction; amide-containing amine; ruthenium; EXAFS spectroscopy; UV-Vis spectroscopy

\section{Introduction}

Since ruthenium $(\mathrm{Ru})$ is used in semiconductors and catalysts, the demand for and price of $\mathrm{Ru}$ have increased greatly in recent years. Recycling of $\mathrm{Ru}$ from spent products is therefore valuable. In the well-known refining process, $\mathrm{Ru}$ is selectively recovered by distillation as $\mathrm{RuO}_{4}[1,2]$. In contrast, the refining of platinum group metals is based mainly on solvent extraction methods. The replacement of distillation by extraction is expected to simplify the purification process. However, there has not been an effective solvent extraction system for $\mathrm{Ru}[1,2]$.

Knowledge of $\mathrm{Ru}$ species in acidic chloride solutions is important for developing effective extractants. Nevertheless, reliable knowledge is rather limited because of the long time required for equilibration of the aquation/chloridation of $\mathrm{Ru}$ ions and the variety of $\mathrm{Ru}$ chloride 
complexes [1-10]. The properties of $\mathrm{Ru}$ species in $\mathrm{HCl}$ were precisely summarized in the thesis of Viljoen [9]. Connick and Fine [6] have reported that the equilibration times for Ru(III) in 0.05 and $0.1 \mathrm{M} \mathrm{HCl}$ solutions are 64 and 74 days, respectively. The $\mathrm{Ru}(\mathrm{III})$ in the $0.05-0.1 \mathrm{M} \mathrm{HCl} \mathrm{forms}$ $\left[\mathrm{RuCl}_{n}\left(\mathrm{H}_{2} \mathrm{O}\right)_{6-n}\right]^{3-n}(n=1-4)$ [7]. In contrast, $\mathrm{Ru}(\mathrm{III})$ in $10 \mathrm{M} \mathrm{HCl}$ exists primarily as $\left[\mathrm{RuCl}_{6}\right]^{3-}[8]$. Although stability constants and absorbtivities $\left(\varepsilon, \mathrm{M}^{-1} \mathrm{~cm}^{-1}\right)$ of $\left[\mathrm{RuCl}_{n}\left(\mathrm{H}_{2} \mathrm{O}\right)_{6-n}\right]^{3-n}(n=1-6)$ have been estimated through polarographic and ultraviolet-visible spectroscopy (UV-Vis) measurements of $\mathrm{Ru}$ species separated by ion-exchange resins [9], the constants are scattered. Viljoen [9] has recently verified the $K$ value for $\left[\mathrm{RuCl}_{6}\right]^{3-} /\left[\mathrm{RuCl}_{5}\left(\mathrm{H}_{2} \mathrm{O}\right)\right]^{2-}$, but no effort has been made to determine the $K$ values for $\left[\mathrm{RuCl}_{n}\left(\mathrm{H}_{2} \mathrm{O}\right)_{6-n}\right]^{3-n} /\left[\mathrm{RuCl}_{n-1}\left(\mathrm{H}_{2} \mathrm{O}\right)_{5-n}\right]$ with lower $n$ and to obtain structural parameters for the complexes in aqueous $\mathrm{HCl}$ solutions.

Because of the inert properties of aqua-chlorido or hexachlorido complexes with trivalent platinum group metal ions [1,2], few extraction studies of $\mathrm{Ru}(\mathrm{III})$ in $\mathrm{HCl}$ solutions have been reported, as is also true for studies of $\mathrm{Rh}(\mathrm{III})$. The mechanism of extraction and structural knowledge of $\mathrm{Ru}(\mathrm{III})$ are also lacking. However, we have already found that $\mathrm{Rh}(\mathrm{III})$ can be successfully extracted with amide-containing amine compounds [11,12].

In the present study, we analyzed Ru complexes in $0.5-10 \mathrm{M} \mathrm{HCl}$ solutions by means of UV-Vis and extended X-ray absorption fine structure (EXAFS) spectroscopies, and we compared Ru(III) extraction properties for $N$-2-ethylhexyl-bis(N-di-2-ethylhexyl-ethylamide) amine (EHBAA, Figure 1$)$, which is an amide-containing amine compound, with those for trioctylamine (TOA, Figure 1). The structural properties of the $\mathrm{Ru}(\mathrm{III})$ complex extracted with EHBAA were also studied using EXAFS spectroscopy.

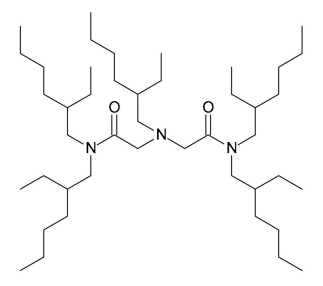

(a)

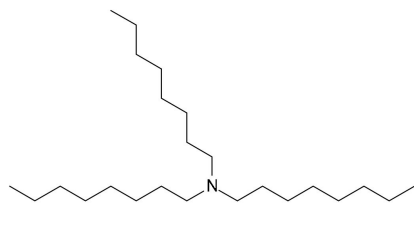

(b)

Figure 1. Structures of (a) N-2-ethylhexyl-bis( $N$-di-2-ethylhexyl-ethylamide) amine (EHBAA) and (b) trioctylamine (TOA).

\section{Materials and Methods}

\subsection{Reagents}

EHBAA and TOA were purchased from Chemicrea Inc. (Tokyo, Japan) and Wako Pure Chemical Industries, Ltd. (Osaka, Japan), respectively, and used without further purification. All $\mathrm{HCl}$ solutions containing $\mathrm{Ru}$ were prepared by using $\mathrm{RuCl}_{3}$ dihydrate (Soekawa Chemicals Inc., Sendai, Japan) and concentrated $\mathrm{HCl}$ (Wako Pure Chemical Industries, Ltd., Osaka, Japan). The solutions were kept in the dark at room temperature. All chemicals were of reagent grade.

\subsection{Measurement of $U V$-Vis Absorption Spectra}

Hydrochloric acid solutions $(0.5-10 \mathrm{M})$ containing $0.9 \mathrm{mM} \mathrm{Ru}$ were prepared and allowed to stand for 1 day to 3 months. Absorption spectra of the sample solutions were collected using a UV-Vis spectrometer (UV-2500PC, Shimadzu Corporation, Kyoto, Japan) and quartz cells with a $0.20 \mathrm{~cm}$ optical path length. Spectra in the range 300-600 nm were analyzed using the Hyperquad program (Protonic Software) [13] to determine the $K$ and $\varepsilon$ values of $\mathrm{Ru}$ chloride complexes. Fitting quality was checked using a least-squares minimization function defined as $S=\sum\left[\left(A b s_{o b s}-A b s_{f i t}\right) /\left(A b s_{o b s}\right)\right]^{2}$, 
where Abs denotes the absorbance of the UV-Vis spectra. The stepwise stability constants of Ru(III) chloride complexes are defined as follows:

$$
K_{n}=\frac{y_{n}\left[\operatorname{RuCl}_{n}\left(\mathrm{H}_{2} \mathrm{O}\right)_{(6-n)}\right]^{3-n}}{y_{n-1}\left[\operatorname{RuCl}_{n-1}\left(\mathrm{H}_{2} \mathrm{O}\right)_{(7-n)}\right]^{4-n} y_{\mathrm{Cl}}[\mathrm{Cl}]}
$$

where $y_{n}$ is activity coefficients of $\left[\mathrm{RuCl}_{n}\left(\mathrm{H}_{2} \mathrm{O}\right)_{6-n}\right]^{3-n}$, and $y_{\mathrm{Cl}}$ is the mean activity coefficient of $\mathrm{HCl}$ determined previously [14]. The $y_{n}$ is defined on basis of the modified Debye-Hückel model which was proposed by Partanen et al. as follows [15,16]:

$$
\log y_{n}=-\frac{A z_{n}^{2} \sqrt{I}}{1+B a_{n} \sqrt{I}}+b_{1} I+b_{2} I^{2}+b_{3} I^{\frac{7}{2}}+\Gamma_{y}
$$

where $z_{n}$ is the valence of $\left[\operatorname{RuCl}_{n}\left(\mathrm{H}_{2} \mathrm{O}\right)_{6-n}\right]^{3-n}, \stackrel{\circ}{n}_{n}$ is the distance of closest approach between the aqueous $\mathrm{Ru}$ species and hydrogen ions, $b_{1}, b_{2}$, and $b_{3}$ are adjustable parameters, $I$ is ionic strength $(\mathrm{mol} / \mathrm{kg})$, and $\Gamma_{y}$ is a molarity conversion factor. The $A$ and $B$ are the Debye-Hückel parameter $A=0.5108(\mathrm{~mol} / \mathrm{kg})^{-1 / 2}$ and the electrolyte-dependent parameters $B=1.4(\mathrm{~mol} / \mathrm{kg})^{-1 / 2}$, respectively. Since the $b$ and $\Gamma_{y}$ terms in Equation (2) are independent of aqueous Ru species, the $y_{n} / y_{n-1}$ is expressed as follows:

$$
\log \frac{y_{n}}{y_{n-1}}=-\frac{A z_{n}^{2} \sqrt{I}}{1+B a_{n} \sqrt{I}}+\frac{A z_{n-1}^{2} \sqrt{I}}{1+B a_{n-1} \sqrt{I}}
$$

The 4 for $\stackrel{\circ}{4}_{4}, 5$ for $\stackrel{\circ}{5}_{5}$, and 9 for $\stackrel{\circ}{6}_{6}$ were used in order to estimate the logarithmic $y_{n} / y_{n-1}$ [17]. In contrast, the $y_{4} / y_{3} y_{\mathrm{Cl}}$ was assumed to be 1 since the $K$ value for $\left[\mathrm{RuCl}_{4}\left(\mathrm{H}_{2} \mathrm{O}\right)_{2}\right]^{-} /\left[\mathrm{RuCl}_{3}\left(\mathrm{H}_{2} \mathrm{O}\right)_{3}\right]$ without involving the $y_{4} / y_{3} y_{C l}$ is constant regardless ionic strength [6].

\subsection{Extraction Procedure}

Solutions of 0.5 M EHBAA or TOA dissolved in chloroform and aqueous $\mathrm{HCl}$ solutions were contacted in $10 \mathrm{~mL}$ glass tubes with a vertical shaker (Yayoi, Tokyo, Japan) (amplitude: $100 \mathrm{~mm}$ and frequency: 200 strokes $/ \mathrm{min}$ ). After centrifugation, $1 \mathrm{~mL}$ of the pre-equilibrated organic phase and an equal volume of $\mathrm{HCl}$ solution containing $1 \mathrm{mM}$ Ru were shaken and then centrifuged. Metal concentrations in the aqueous solution were determined using an inductively coupled plasma atomic emission spectrometer (Ultima2, Horiba, Ltd., Kyoto, Japan). Extraction percentages were calculated on the basis of the mass balance of Ru in the aqueous phases.

\subsection{XAFS Measurements}

$\mathrm{HCl}$ solutions $(0.7-10 \mathrm{M})$ containing $0.1 \mathrm{M} \mathrm{Ru}(\mathrm{III})$ were allowed to stand for two weeks. A dodecane solution containing $\mathrm{Ru}(\mathrm{III})$ and $0.5 \mathrm{M}$ EHBAA were prepared by extraction of $\mathrm{Ru}$ $(0.1 \mathrm{M})$ in $5 \mathrm{M} \mathrm{HCl}$ with a 6-h shaking time. The XAFS measurements were carried out on the BL11XU beamline at the SPring-8 synchrotron radiation facility. The synchrotron radiation was monochromatized using a $\mathrm{Si}(111)$ crystal. The Ru K-edge absorption spectra were collected in transmission mode using a plastic cell with a path length of 5 or $10 \mathrm{~mm}$. Energy calibrations were performed using Ru metal (22117 eV) [18]. The EXAFS signal was extracted from the raw absorption spectra by spline approximation for atomic absorption background using the ATHENA software package (version 0.8.056) [19], and then the signals, weighted by $k^{3}$, were windowed using the Hann function. Data fitting was performed with the ARTHEMIS software package (version 0.8.012) [19]. The theoretical phases and amplitudes were calculated with FEFF6 on the basis of the structure of $\left[\mathrm{Ru}\left(\mathrm{H}_{2} \mathrm{O}\right)_{6}\right]^{3+}$ and $\left[\mathrm{RuCl}_{6}\right]^{3-}$ [20-22]. Since the coordination number of $\mathrm{Ru}^{3+}$ in aqueous solution has been reported to be $6[9,21,22]$, that of $\mathrm{Ru}$ in the sample solutions was fixed at 6 . The number of $\mathrm{Cl}$ 
$\left(N_{\mathrm{Cl}}\right)$ in the $10 \mathrm{M} \mathrm{HCl}$ system was fixed at 6 on the basis of the similarity of the UV-Vis spectra of 8-10 M HCl solutions in our system and the $\mathrm{N}_{\mathrm{Cl}}$ of $\left[\mathrm{RuCl}_{6}\right]^{3-}$ assigned by Jorgensen [8]. The amplitude reduction factor was determined in the fit of $\mathrm{Ru}^{3+}$ in the $10 \mathrm{M} \mathrm{HCl}$ solution, and the obtained value (1.0) was applied in all the data fits. The values of the square of the Debye-Waller factor $\left(\sigma^{2}\right)$ of the $\mathrm{Ru}-\mathrm{Cl}$ (0.0039) and Ru-O (0.0014) shells obtained in the fit of the $10 \mathrm{M} \mathrm{HCl}$ solution and $1 \mathrm{M} \mathrm{HCl}$ systems, respectively, were also fixed in the fits of the aqueous system. The standard deviations were determined with an $F$ test (95\% confidence) [23], and fitting quality was checked using the $R$-factor defined as $R=\left\{\sum\left(\left[\operatorname{Re}_{\mathrm{fit}}\right]^{2}+\left[\mathrm{Im}_{\mathrm{fit}}\right]^{2}\right) / \sum\left(\left[\mathrm{Re}_{\mathrm{obs}}\right]^{2}+\left[\operatorname{Im}_{\mathrm{obs}}\right]^{2}\right)\right.$, where Re and Im denote the real and imaginary parts of EXAFS.

\subsection{Fourier-Transform Infrared (FT-IR) Spectroscopy Measurements}

Dodecane solution containing $\mathrm{Ru}(\mathrm{III})$ and $0.5 \mathrm{M}$ EHBAA were prepared in a similar manner as the XAFS sample. The FT-IR spectrum of the sample solution was recorded in the range $600-4000 \mathrm{~cm}^{-1}$ with a resolution of $4 \mathrm{~cm}^{-1}$ using an attenuated total reflection method with an FT-IR spectrometer (Spectrum 100, Perkin Elmer, Waltham, MA, USA). The data collection was repeated 16 times, and the results were merged.

\section{Results and Discussion}

\subsection{Analysis of Ru Species in Aqueous $\mathrm{HCl}$}

\subsubsection{Estimation of Equilibration Time for Aquation/Chloridation of $\mathrm{Ru}$}

The equilibration times for the ligand exchange reactions of $\mathrm{Ru}$ between $\mathrm{H}_{2} \mathrm{O}$ and $\mathrm{Cl}^{-}$after the dissolution of $\mathrm{RuCl}_{3}$ dihydrate into aqueous $\mathrm{HCl}$ solutions were estimated from the time-dependent UV-Vis spectra. The results at $1 \mathrm{M} \mathrm{HCl}$ are shown in Figure 2. An absorption band around $360 \mathrm{~nm}$ appeared in the spectrum after a storage time of one day, and it became weaker with increasing storage time. The similarity of the UV-Vis spectral shapes on days 13-27 indicated that the aquation/chloridation of $\mathrm{Ru}$ in $1 \mathrm{M} \mathrm{HCl}$ solution attained equilibrium within 13 days. The same approach was used to investigate the equilibration times at various $\mathrm{HCl}$ concentrations. Figures S1-S7 show time-dependent UV-Vis spectra for Ru solutions of $0.5,0.7,2,3,5,7$, and $10 \mathrm{M}$ $\mathrm{HCl}$. The time required for equilibration was drastically shortened with increasing $\mathrm{HCl}$ concentration. This phenomenon is likely to be due to the fact that the anation rate is much faster for $\left[\mathrm{RuCl}_{5}\left(\mathrm{H}_{2} \mathrm{O}\right)\right]^{2-}$ than for $\left[\mathrm{RuCl}_{n}\left(\mathrm{H}_{2} \mathrm{O}\right)_{6-n}\right]^{3-n}$ with lower $n[9,24]$.

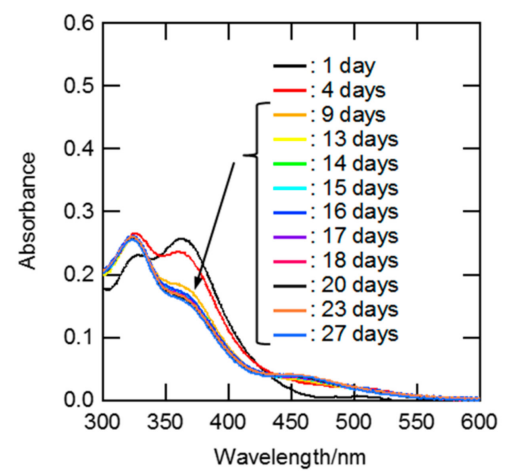

Figure 2. UV-Vis spectra for the Ru solution of $1.0 \mathrm{M} \mathrm{HCl}$ at various standing times. [Ru] $=0.9 \mathrm{mM}$, standing time: $1,4,9,13,14,15,16,17,18,20,23$, and 27 days, and optical path length: $0.20 \mathrm{~cm}$.

\subsubsection{Speciation of Ru Species}

XAFS measurements of $0.1 \mathrm{M} \mathrm{Ru}$ solutions at $0.7-10 \mathrm{M} \mathrm{HCl}$ were performed to clarify the inner coordination sphere of the Ru. The X-ray absorption near edge structure (XANES) spectra 
in the $\mathrm{Ru}$ solutions were similar to that in solid $\mathrm{RuCl}_{3}$ dihydrate, whereas those of $\mathrm{Ru}$ metal and $\mathrm{RuO}_{2}$ were different (see Figure S8). These results clearly indicated that $\mathrm{Ru}$ in the $0.7-10 \mathrm{M} \mathrm{HCl}$ solutions was trivalent. Figure $3 \mathrm{a}, \mathrm{b}$ and Figure S9 show the Ru K-edge $\mathrm{k}^{3}$-weighted EXAFS and their FT spectra. In the FT spectra shown in Figure 3b, the intense peak (1.9 A) gradually changed with increasing $\mathrm{HCl}$ concentration. The absence of other peaks in the longer $R$ range indicated that the $\mathrm{Ru}(\mathrm{III})$ in the sample solutions were mononuclear complexes but not polynuclear. The intense peak was broader for $0.7 \mathrm{M} \mathrm{HCl}$ than for $10 \mathrm{M} \mathrm{HCl}$. To clarify the presence of $\mathrm{Cl}^{-}$and $\mathrm{H}_{2} \mathrm{O}$ in the inner coordination sphere of $\mathrm{Ru}^{3+}, 2$-shell fit $(\mathrm{Cl}$ and $\mathrm{O})$ was performed. Table 1 lists the structural parameters obtained from the fits. The number of oxygens $\left(N_{\mathrm{O}}\right)$ and $N_{\mathrm{Cl}}$ decreased and increased, respectively, with increasing $\mathrm{HCl}$. The EXAFS fitting results revealed that the anionic species in $\left[\mathrm{RuCl}_{n}\left(\mathrm{H}_{2} \mathrm{O}\right)_{6-n}\right]^{3-n}(n=4-6)$ were present primarily in the $0.7-10 \mathrm{M} \mathrm{HCl}$ solutions.

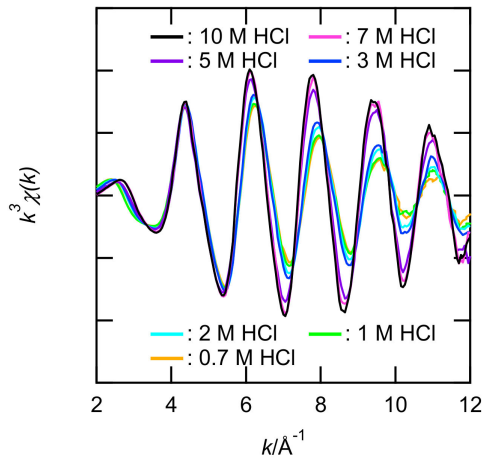

(a)

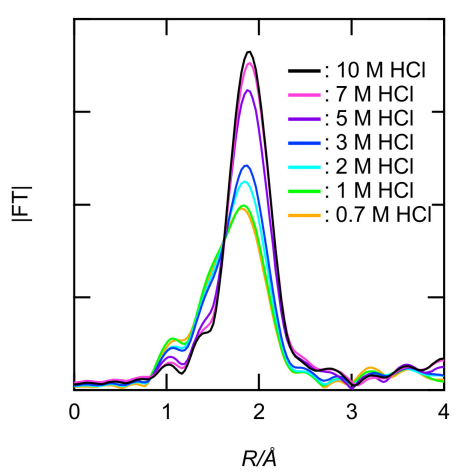

(b)

Figure 3. (a) The Ru K-edge $\mathrm{k}^{3}$-weighted extended X-ray absorption fine structure (EXAFS) spectra and (b) the corresponding Fourier transforms (FTs) for the $\mathrm{Ru}(\mathrm{III})$ in $0.7-10 \mathrm{M} \mathrm{HCl}$ solutions. The phase shifts are not corrected.

Table 1. The Ru K-edge EXAFS structural parameters for $\mathrm{Ru}^{3+}$ in $\mathrm{HCl}$ solutions.

\begin{tabular}{ccccccc}
\hline HCl Conc. & Path & $\boldsymbol{N}^{a}$ & $\boldsymbol{R}(\AA \mathbf{\AA})$ & $\boldsymbol{\sigma}^{\mathbf{2}}\left(\AA^{\mathbf{2}}\right)^{b}$ & $\Delta \boldsymbol{E}(\mathbf{e V})^{c}$ & $\boldsymbol{R}$-Factor \\
\hline $0.7 \mathrm{M}$ & $\mathrm{Ru}-\mathrm{Cl}$ & $3.7(1)$ & $2.343(3)$ & $0.0039^{d}$ & -1.5 & 0.018 \\
& $\mathrm{Ru}-\mathrm{O}$ & $2.3(1)$ & $2.055(6)$ & $0.0014^{d}$ & & \\
$1.0 \mathrm{M}$ & $\mathrm{Ru}-\mathrm{Cl}$ & $3.7(1)$ & $2.342(3)$ & $0.0039^{d}$ & -1.8 & 0.018 \\
& $\mathrm{Ru}-\mathrm{O}$ & $2.3(1)$ & $2.056(6)$ & $0.0014(8)$ & & \\
$2.0 \mathrm{M}$ & $\mathrm{Ru}-\mathrm{Cl}$ & $4.0(1)$ & $2.350(3)$ & $0.0039^{d}$ & 0.1 & 0.011 \\
& $\mathrm{Ru}-\mathrm{O}$ & $2.0(1)$ & $2.065(7)$ & $0.0014^{d}$ & & \\
$3.0 \mathrm{M}$ & $\mathrm{Ru}-\mathrm{Cl}$ & $4.3(1)$ & $2.351(3)$ & $0.0039^{d}$ & 0.2 & 0.010 \\
& $\mathrm{Ru}-\mathrm{O}$ & $1.7(1)$ & $2.062(8)$ & $0.0014^{d}$ & & \\
$5.0 \mathrm{M}$ & $\mathrm{Ru}-\mathrm{Cl}$ & $5.4(1)$ & $2.367(2)$ & $0.0039^{d}$ & 0.7 & 0.007 \\
& $\mathrm{Ru}-\mathrm{O}$ & $0.6(1)$ & $2.10(1)$ & $0.0014^{d}$ & & \\
$7.0 \mathrm{M}$ & $\mathrm{Ru}-\mathrm{Cl}$ & $5.7(1)$ & $2.374(2)$ & $0.0039^{d}$ & 2.3 & 0.009 \\
& $\mathrm{Ru}-\mathrm{O}$ & $0.3(1)$ & $2.13(3)$ & $0.0014^{d}$ & & \\
$10 \mathrm{M}$ & $\mathrm{Ru}-\mathrm{Cl}$ & 6.0 & $2.371(2)$ & $0.0039(2)$ & 1.3 & 0.009 \\
$\left.[\mathrm{RuCl}]_{6}\right]^{3-e}$ & $\mathrm{Ru}-\mathrm{Cl}$ & 6 & $2.3789^{8}$ & & & \\
{$\left[\mathrm{Ru}\left(\mathrm{H}_{2} \mathrm{O}\right)_{6}\right]^{3+f}$} & $\mathrm{Ru}-\mathrm{O}$ & 6 & 2.029 & & & \\
\hline
\end{tabular}

$[\mathrm{Ru}]=0.1 \mathrm{M} .{ }^{\text {a }}$ Set as a sum equal to $6\left(\mathrm{~N}\right.$ of $\mathrm{Ru}-\mathrm{Cl}+\mathrm{N}$ of Ru-O). ${ }^{\mathrm{b}}$ Parameter due to thermal or structural disorder. ${ }^{c}$ Energy shift parameter ${ }^{d}$ Fixed parameter. ${ }^{e}$ Ref. [22]. ${ }^{f}$ Ref. [21]. ${ }^{g}$ Average bond distances. The amplitude reduction factor was fixed at 1.0. Estimated errors in parentheses. The $k$-range for the Fourier transformation: 2.0-12.0 $\AA^{-1}$; the curve-fitting $R$-range: $1-3 \AA$.

The speciation of $\mathrm{Ru}$ was also investigated by means of UV-Vis spectroscopy. Figure 4a shows UV-Vis spectra for Ru(III) solutions in 0.5-10 M HCl. All the sample solutions were allowed to stand for 3 months. Three characteristic bands in the range 300-360 nm appeared in the spectra shown in Figure 4a. According to ref. 9, $\left[\mathrm{RuCl}_{4}\left(\mathrm{H}_{2} \mathrm{O}\right)_{2}\right]^{-}$and $\left[\mathrm{RuCl}_{5}\left(\mathrm{H}_{2} \mathrm{O}\right)\right]^{2-}$ have an adsorption band around $320 \mathrm{~nm}$, whereas $\left[\mathrm{RuCl}_{6}\right]^{3-}$ has bands around 310 and $350 \mathrm{~nm}$. The stepwise stability constants of $\left[\mathrm{RuCl}_{n}\left(\mathrm{H}_{2} \mathrm{O}\right)_{6-n}\right]^{3-n}$ were estimated using spectra shown in Figure S10. Reasonable results with a lower $S$ value and positive $\varepsilon$ were obtained through calculations involving the equilibrium of $K_{4}, K_{5}$, and $K_{6}$. The obtained constants were $0.408 \pm 0.005$ for $\log K_{4},-0.642 \pm 0.005$ for $\log K_{5}$, and $-1.48 \pm 0.02$ for $\log K_{6}$. 
Figure $4 \mathrm{~b}$ shows the $\varepsilon$ values for each of the $\mathrm{Ru}(\mathrm{III})$ chloride complexes. The wavelength of the band and $\varepsilon$ for the $\left[\mathrm{RuCl}_{4}\left(\mathrm{H}_{2} \mathrm{O}\right)_{2}\right]^{-}$, $\left[\mathrm{RuCl}_{5}\left(\mathrm{H}_{2} \mathrm{O}\right)\right]^{2-}$, and $\left[\mathrm{RuCl}_{6}\right]^{3-}$ were consistent with those determined in the previous studies [9], whereas the $\varepsilon$ for $\left[\mathrm{RuCl}_{3}\left(\mathrm{H}_{2} \mathrm{O}\right)_{3}\right]$ resembled the $\varepsilon$ for the facial complex rather than the meridional complex. The speciation diagram of $\mathrm{Ru}(\mathrm{III})$ species shown in Figure $4 \mathrm{c}$ were produced on the basis of the stability constants found in this study.

The distribution profile was slightly different from those in the former report, i.e., the portion of $\left[\mathrm{RuCl}_{5}\left(\mathrm{H}_{2} \mathrm{O}\right)\right]^{2-}$ in our diagram was higher, around $5 \mathrm{M} \mathrm{HCl}$ [9]. Figure 5 shows the $N_{\mathrm{Cl}}$ numbers in $\left[\mathrm{RuCl}_{n}\left(\mathrm{H}_{2} \mathrm{O}\right)_{6-n}\right]^{3-n}$, which were evaluated using the fractions of each Ru species, and those of the EXAFS fits along with those calculated by Viljoen [9]. The $N_{\mathrm{Cl}}$ in our systems had an analogous dependence on the $\mathrm{HCl}$ concentrations and were higher than those in the other system. The similarity of $N_{\mathrm{Cl}}$ indicated that the assumption of $y_{4} / y_{3} y_{\mathrm{Cl}}$ is reasonable.

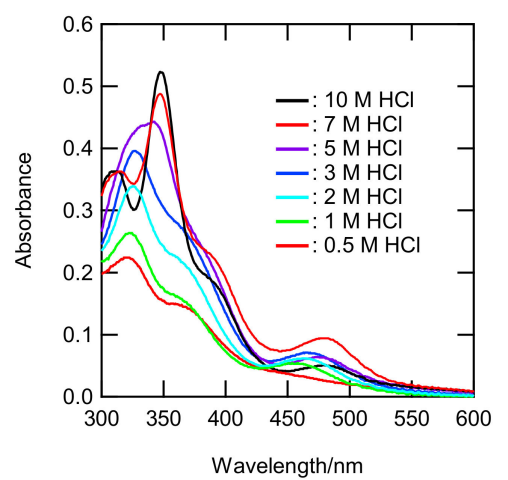

(a)

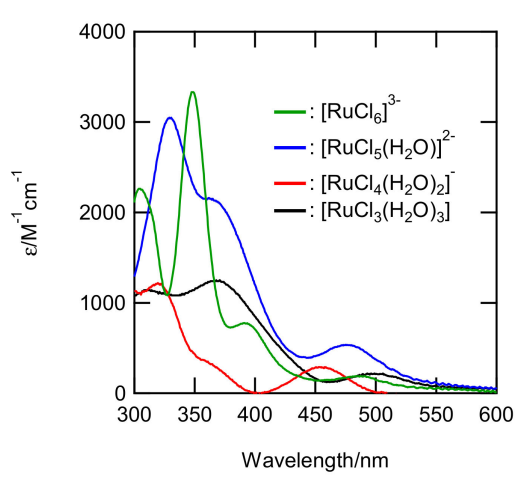

(b)

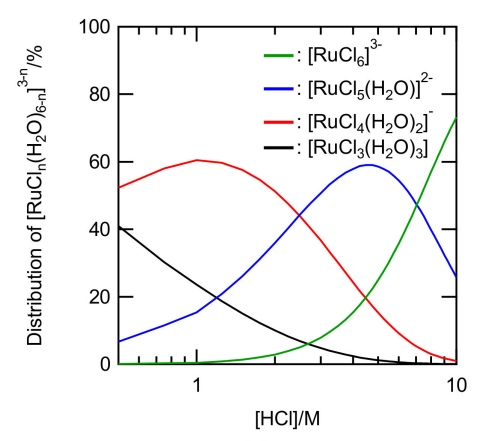

(c)

Figure 4. (a) The UV-Vis spectra of $\mathrm{HCl}$ solutions $(0.5-10 \mathrm{M})$ containing $0.9 \mathrm{mM} \mathrm{Ru}(\mathrm{III})$; (b) the $\varepsilon$, and (c) distribution percentages of $\left[\mathrm{RuCl}_{n}\left(\mathrm{H}_{2} \mathrm{O}\right)_{6-n}\right]^{3-n}(n=3-6)$ obtained from their spectra.

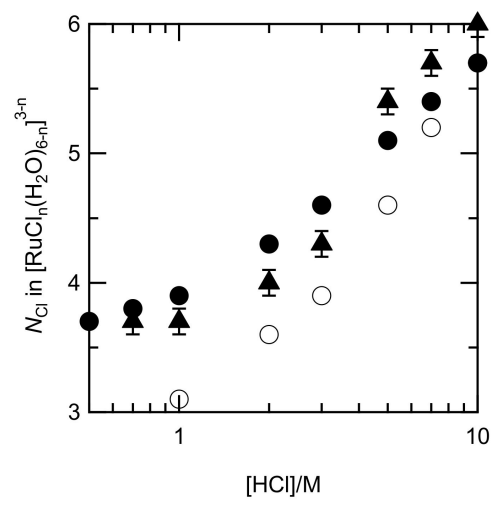

Figure 5. Correlation between the $N_{\mathrm{Cl}}$ in $\left[\mathrm{RuCl}_{n}\left(\mathrm{H}_{2} \mathrm{O}\right)_{6-n}\right]^{3-n}$ and $\mathrm{HCl}$ concentration. Calculated data from our stability constants (filled circles); fitting results in the EXAFS analysis (filled triangles); and calculated data by Viljoen [9] (circles). 


\section{2. $R$ u(III) Extraction Studies}

\subsubsection{Extraction Ability of EHBAA}

The EXAFS and UV-Vis studies revealed that predominant $\mathrm{Ru}(\mathrm{III})$ complexes in $0.5-10 \mathrm{M} \mathrm{HCl}$ were anionic. We attempted to extract the $\mathrm{Ru}(\mathrm{III})$ complexes using EHBAA, which has a high affinity for the $\mathrm{Rh}(\mathrm{III})$-chlorido anion [11,12]. The shaking time was $6 \mathrm{~h}$, a time sufficient for the $\mathrm{Ru}(\mathrm{III})$ extraction in the EHBAA system to reach equilibrium (see Figure S11). Figure 6 shows Ru extraction percentages $(E \%)$ in the EHBAA and TOA systems at $0.5-10 \mathrm{M} \mathrm{HCl}$. The $E \%$ for the EHBAA gradually increased with $\mathrm{HCl}$ concentration, reached a maximum at $5 \mathrm{M}$, and then decreased, whereas the $E \%$ for the TOA was small over the entire range of $\mathrm{HCl}$ concentrations. The amide groups in the EHBAA may strongly affect the $\mathrm{Ru}(\mathrm{III})$ chlorido anion. This effect has been observed in the study of $\mathrm{Rh}(\mathrm{III})$ extraction using amide-containing amine compounds [11,12]. The profile of $E \%$ in the EHBAA system versus $\mathrm{HCl}$ concentration closely resembled that of the distribution percentages in the $\left[\mathrm{RuCl}_{5}\left(\mathrm{H}_{2} \mathrm{O}\right)\right]^{2-}$ in Figure 4. Therefore, the EHBAA may preferentially extract the pentachlorido anion.

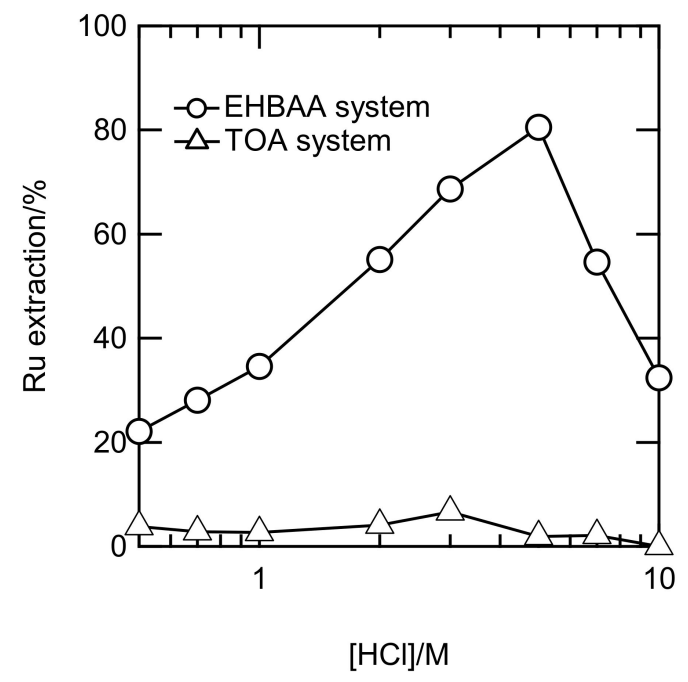

Figure 6. Extraction percentages of $\mathrm{Ru}$ with $0.5 \mathrm{M} \mathrm{EHBAA}$ and $\mathrm{TOA}$ in $\mathrm{CHCl}_{3}$ versus $\mathrm{HCl}$ concentration. $[\mathrm{Ru}]=1 \mathrm{mM}$; shaking time $=6 \mathrm{~h}$.

\subsubsection{Structural Study of Ru Extracted by EHBAA}

EXAFS studies of $\mathrm{Ru}(\mathrm{III})$ complexes extracted with EHBAA were performed to obtain data relevant to the extraction mechanism. The diluent of the XAFS sample was dodecane because of the high absorptivity of $\mathrm{CHCl}_{3}$ for X-rays. Figure 7 shows the FT spectra of the Ru K-edge $k^{3}$-weighted EXAFS for the extracted complex. One-shell fits $(\mathrm{Cl})$ and 2-shell fits $(\mathrm{Cl}$ and $\mathrm{O})$ were performed to verify the inner coordination sphere of the extracted complexes. The 2-shell fits gave reasonable structural parameters and the low $R$-factor listed in Table 2. Since the $N$ was 4.7 for $\mathrm{Cl}$ and 1.3 for $\mathrm{O}$, the $\mathrm{Ru}(\mathrm{III})$ complex in the EHBAA phase is likely a pentachloride anion.

FT-IR measurements of the extracted $\mathrm{Ru}(\mathrm{III})$ complex were performed to confirm whether amide groups in the EHBAA coordinate to $\mathrm{Ru}^{3+}$ or not. No significant shifts of the peak corresponding to amide groups were observed with the extraction of $\mathrm{Ru}(\mathrm{III})$ (see Figure S12). Considering the EHBAA are protonated by the $\mathrm{HCl}$ extraction [25], the following equation can be proposed:

$$
\left[\mathrm{RuCl}_{5}\left(\mathrm{H}_{2} \mathrm{O}\right)\right]^{2-}+2[\text { EHBAA.HCl }] \rightleftharpoons\left[\mathrm{RuCl}_{5}\left(\mathrm{H}_{2} \mathrm{O}\right)\right](\mathrm{H} \cdot \mathrm{EHBAA})_{2}+2 \mathrm{Cl}^{-}
$$


Outer-sphere interactions between the $\mathrm{Ru}$ complex anion and the protonated ligands can contribute the formation of stable Ru complex in the organic phase as in the previous study regarding Pt(IV) extractions [26].

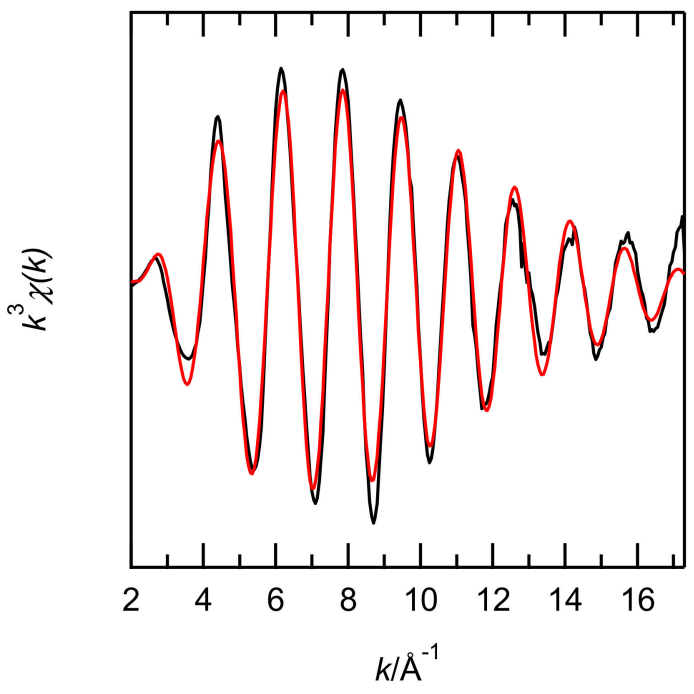

(a)

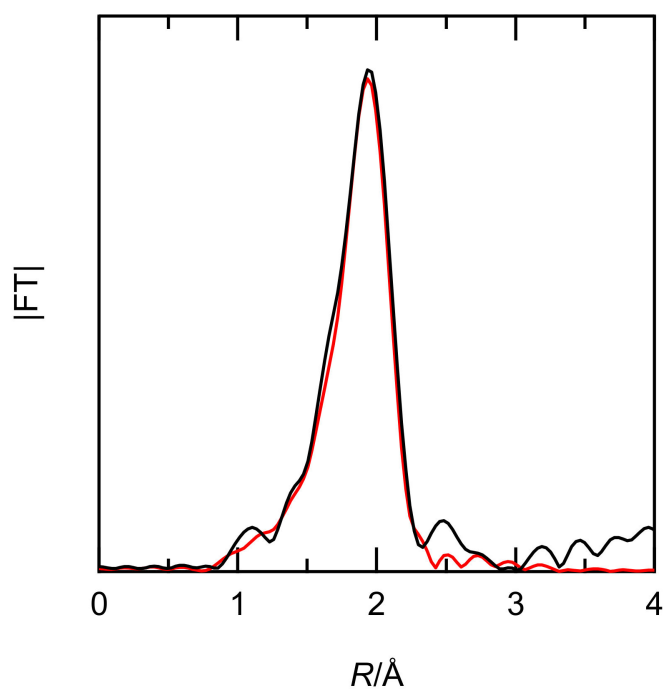

(b)

Figure 7. Comparison of the Ru K-edge $\mathrm{k}^{3}$-weighted EXAFS (a) and its FT spectra (b) for the EHBAA phase obtained after extraction with $0.1 \mathrm{M} \mathrm{Ru}(\mathrm{III})$ in $5 \mathrm{M} \mathrm{HCl}$ solutions. Experimental data (black line) and theoretical fit (red line) are shown. The phase shifts are not corrected.

Table 2. The Ru K-edge EXAFS structural parameters for extracted $\mathrm{Ru}^{3+}$ complex in dodecane solution.

\begin{tabular}{ccccccc}
\hline Sample & Path & $N^{a}$ & $\boldsymbol{R}(\AA)$ & $\boldsymbol{\sigma}^{2}\left(\AA^{2}\right)$ & $\Delta E(\mathbf{e V})$ & $\boldsymbol{R}$-Factor \\
\hline EHBAA phase & $\mathrm{Ru}-\mathrm{Cl}$ & $4.7(2)$ & $2.370(3)$ & $0.0036(3)$ & 3.3 & 0.016 \\
& $\mathrm{Ru}-\mathrm{O}$ & $1.3(2)$ & $2.20(1)$ & $0.0010^{b}$ & & \\
\hline
\end{tabular}

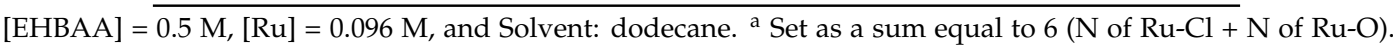
${ }^{b}$ Fixed parameter. The amplitude reduction factor was fixed at 1.0. Estimated errors in parentheses. The $k$-range for the Fourier transformation: $2.0-17.3 \AA^{-1}$; the curve-fitting R-range: $1-3 \AA$.

\section{Conclusions}

The properties of the $\mathrm{Ru}$ complexes in $\mathrm{HCl}$ solutions and the EHBAA phases were investigated by means of UV-Vis and Ru K-edge EXAFS spectroscopies. Although the equilibration of Ru after the dissolution of $\mathrm{RuCl}_{3}$ dihydrate into aqueous $\mathrm{HCl}$ solution was achieved in 30 days at $0.5 \mathrm{M} \mathrm{HCl}$, that time became considerably shorter with increasing $\mathrm{HCl}$ concentrations. Spectral changes in the $\mathrm{Ru}$ K-edge EXAFS and its FT spectra as well as those in its UV-Vis spectra were observed with increasing $\mathrm{HCl}$ concentration. The $\mathrm{Ru}$ in $\mathrm{HCl}$ solutions forms anionic chlorido complexes, and the predominant species in $0.5-10 \mathrm{M} \mathrm{HCl}$ solutions are $\left[\mathrm{RuCl}_{4}\left(\mathrm{H}_{2} \mathrm{O}\right)_{2}\right]^{-}$at $0.5-2 \mathrm{M} \mathrm{HCl},\left[\mathrm{RuCl}_{5}\left(\mathrm{H}_{2} \mathrm{O}\right)\right]^{2-}$ at 3-5 $\mathrm{M} \mathrm{HCl}$, and $\left[\mathrm{RuCl}_{6}\right]^{3-}$ at 7-10 $\mathrm{M} \mathrm{HCl}$.

The inner coordination sphere of the Ru complex extracted with EHBAA in $5 \mathrm{M} \mathrm{HCl}$ was also investigated on the basis of the Ru K-edge EXAFS spectra. The curve fit indicated that the $N$ were 4.7 for $\mathrm{Cl}$ and 1.3 for $\mathrm{O}$. The pattern of the $E \%$ of $\mathrm{Ru}$ in the EHBAA system was similar to that of the percentages of $\left[\mathrm{RuCl}_{5}\left(\mathrm{H}_{2} \mathrm{O}\right)\right]^{2-}$ on $\left[\mathrm{RuCl}_{n}\left(\mathrm{H}_{2} \mathrm{O}\right)_{6-n}\right]^{3-n}$; those percentages increased with $\mathrm{HCl}$ concentration, reached a maximum at $5 \mathrm{M} \mathrm{HCl}$, and decreased at higher $\mathrm{HCl}$ concentrations. Therefore, the $\mathrm{Ru}$ in the EHBAA system is probably extracted through formation of ion-pair complexes between the pentachlorido ruthenate anion and two protonated EHBAAs. 
Supplementary Materials: The following are available online at https:/ /www.mdpi.com/2075-4701/8/7/558/s1. Figure S1: UV-Vis spectra for a $0.5 \mathrm{M} \mathrm{HCl}-\mathrm{Ru}$ solution at various standing times. Figure S2: UV-Vis spectra for a $0.7 \mathrm{M} \mathrm{HCl}-\mathrm{Ru}$ solution at various standing times. Figure S3: UV-Vis spectra for a $2.0 \mathrm{M} \mathrm{HCl}-\mathrm{Ru}$ solution at various standing times. Figure S4: UV-Vis spectra for a $3.0 \mathrm{M} \mathrm{HCl}-\mathrm{Ru}$ solution at various standing times. Figure S5: UV-Vis spectra for a 5.0 M HCl-Ru solution at various standing times. Figure S6: UV-Vis spectra for a 7.0 M HCl-Ru solution at various standing times. Figure S7: UV-Vis spectra for a $10 \mathrm{M} \mathrm{HCl}-\mathrm{Ru}$ solution at various standing times. Figure S8: Comparison of XANES spectra for Ru complexes in aqueous and organic solutions with those of $\mathrm{Ru}$ metal, $\mathrm{RuCl}_{3}$ dihydrate, and $\mathrm{RuO}_{4}$. Figure S9: (a) The Ru K-edge $\mathrm{k}^{3}$-weighted EXAFS spectra and (b) the corresponding Fourier transforms for the $\mathrm{Ru}(\mathrm{III})$ in $0.7-10 \mathrm{M} \mathrm{HCl}$ solutions. Figure S10: The UV-Vis spectra of $\mathrm{HCl}$ solutions $(0.5-10 \mathrm{M})$ containing $0.9 \mathrm{mM} \mathrm{Ru}(\mathrm{III})$. Figure S11: Extraction percentages of Ru with 0.5 M EHBAA and TOA in $\mathrm{CHCl}_{3}$ against shaking time. Figure S12: The FT-IR spectra of dodecane containing $0.5 \mathrm{M}$ EHBAA with pre-equilibrium by $\mathrm{HCl}$ and that medium posterior to extraction of $\mathrm{Ru}(\mathrm{III})$ in $5 \mathrm{M} \mathrm{HCl}$.

Author Contributions: T.S., T.O., M.T., and H.N. contributed the data analysis of UV-Vis and EXAFS spectra and discussion about the Ru extraction behaviors and speciation of $\mathrm{Ru}$ species in the aqueous and organic species; T.K., H.S., and T.Y. contributed the XAFS measurements; T.S. and H.N. performed all the experiments and wrote the paper.

Funding: This research was supported by the Environment Research and Technology Development Fund (3K163010) of the Environmental Restoration and Conservation Agency of Japan.

Acknowledgments: The authors thank Hiroko Niiyama for her technical assistance. A part of this work was performed under the Shared Use Program of the Japan Atomic Energy Agency (JAEA) Facilities (proposal nos. 2015A-E05, 2016B-E01, and 2017B-E01) supported by the JAEA Advanced Characterization Nanotechnology Platform as a program of "Nanotechnology Platform" of the Ministry of Education, Culture, Sports, Science and Technology (MEXT), Japan. The synchrotron radiation experiments were performed at the JAEA Beamline BL11XU in SPring-8 (proposal nos. 2015A3515, 2016B3512, and 2017B3531).

Conflicts of Interest: The authors declare no conflict of interest.

\section{References}

1. Cox, M. Solvent Extraction in Hydrometallurgy. In Solvent Extraction Principles and Practice, 2nd ed.; Rydberg, J., Cox, M., Musikas, C., Choppin, G.R., Eds.; Marcel Dekker, Inc.: New York, NY, USA, 2004; pp. 455-506. ISBN 0-8247-5063-2.

2. Bernardis, F.L.; Grant, R.A.; Sherrington, D.C. A review of methods of separation of the platinum-group metals through their chloro-complexes. React. Funct. Polym. 2005, 65, 205-217. [CrossRef]

3. Rechnitz, G.A.; Goodkin, S.C. Some properties of ruthenium(III) and (IV) in acid solution. Platin. Met. Rev. 1963, 7, 25-29.

4. Pantani, F. The behaviour of ruthenium trichloride in aqueous solutions. J. Less-Common Met. 1962, 4, 116-123. [CrossRef]

5. Cady, H.H.; Connick, R.E. The determination of the formulas of aqueous ruthenium(III) species by means of ion-exchange resin: $\mathrm{Ru}^{+3}, \mathrm{RuCl}^{+2}$ and $\mathrm{RuCl}_{2}{ }^{+}$. J. Am. Chem. Soc. 1958, 80, 2646-2652. [CrossRef]

6. Connick, R.E.; Fine, D.A. The identification of neutral ruthenium(III) chloride complexes: Equilibria involving neutral and cationic species. J. Am. Chem. Soc. 1960, 83, 3414-3416. [CrossRef]

7. Taqui Khan, M.M.; Ramachandraiah, G.; Prakash, R. Ruthenium(III) chloride in aqueous solution: Electrochemical and spectral studies. Inorg. Chem. 1986, 25, 665-670. [CrossRef]

8. Jorgensen, C.K. Complexes of the $4 \mathrm{~d}$ - and 5d-groups II. Crystal field and electron transfer spectra of ruthenium(II) and (III), iridium(IV) and platinum(IV). Acta Chem. Scand. 1956, 10, 518-534. [CrossRef]

9. Viljoen, K. Ruthenium(III) Aqua-Chloro Complex Chemistry: The Interconversion of the Hexachlororuthenate(III) and Aquapentachlororuthenate(III) Species. Master's Thesis, University of Stellenbosch, Stellenbosch, South Africa, December 2003.

10. Rard, J.A. Chemistry and thermodynamics of ruthenium and some of its inorganic compounds and aqueous species. Chem. Rev. 1985, 85, 1-39. [CrossRef]

11. Narita, H.; Morisaku, K.; Tanaka, M. The first effective extractant for trivalent rhodium in hydrochloric acid solution. Chem. Commun. 2008, 5921-5923. [CrossRef] [PubMed]

12. Narita, H.; Morisaku, K.; Tanaka, M. Highly efficient extraction of rhodium(III) from hydrochloric acid solution with amide-containing amine compounds. Solvent Extr. Ion Exch. 2015, 33, 407-417. [CrossRef]

13. Gans, P.; Sabatini, A.; Vacca, A. Investigation of equilibria in solution. Determination of equilibrium constants with the HYPERQUAD suite of programs. Talanta 1996, 43, 1739-1753. [CrossRef] 
14. Lobo, V.M.M. Handbook of Electrolyte Solutions Part A; Elsevier: New York, NY, USA, 1989; pp. 515-572. ISBN 0-444-98847-5.

15. Partanen, J.I.; Juusola, P.M.; Vahteristo, K.P.; de Mendonca, A.J.G. Re-evaluation of activity coefficients of aqueous hydrochloric acid solutions up to a molality of $16.0 \mathrm{~mol} \cdot \mathrm{kg}^{-1}$ using the Hückel and Pitzer equations at temperatures from 0 to $50{ }^{\circ} \mathrm{C}$. J. Solut. Chem. 2007, 36, 39-59. [CrossRef]

16. Uchikoshi, M. Determination of the distribution of cupric chloro-complexes in hydrochloric acid solutions at 298 K. J. Solut. Chem. 2017, 46, 704-719. [CrossRef]

17. Kielland, J. Individual activity coefficients of ions in aqueous solutions. J. Am. Chem. Soc. 1937, 59, 1675-1678. [CrossRef]

18. Mo, Y.; Antonio, M.R.; Scherson, D.A. In situ Ru K-edge X-ray absorption fine structure studies of electroprecipitated ruthenium dioxide films with relevance to supercapacitor applications. J. Phys. Chem. B 2000, 104, 9777-9779. [CrossRef]

19. Ravel, B.; Newville, M. ATHENA, ARTEMIS, HEPHAESTUS: Data analysis for X-ray absorption spectroscopy using IFEFFIT. J. Synchrotron Radiat. 2005, 12, 537-541. [CrossRef] [PubMed]

20. Rehr, J.J.; de Leon, J.M.; Zabinsky, S.I.; Albers, R.C. Theoretical X-ray absorption fine structure standards. J. Am. Chem. Soc. 1991, 113, 5135-5140. [CrossRef]

21. Cotton, S.A. Chemistry of Precious Metals; Blackie Academic and Professional: London, UK, 1997; pp. 1-77. ISBN 0-7514-0413-6.

22. Kahrovic, E.; Orioli, P.; Bruni, B.; Vaira, M.D.; Messori, L. Crystallographic evidence for decomposition of dimethylformamide in the presence of ruthenium(III) chloride. Inorg. Chim. Acta 2003, 355, 420-423. [CrossRef]

23. Klementev, K.V. Statistical evaluations in fitting problems. J. Synchrotron Radiat. 2001, 8, 270-272. [CrossRef] [PubMed]

24. Taqui Khan, M.M.; Ramachandraiah, G.; Shukla, R.S. Ruthenium(III) chloride in aqueous solution: Kinetics of the aquation and anation reactions of the chloro complexes. Inorg. Chem. 1988, 27, 3274-3278. [CrossRef]

25. Maeda, M.; Narita, H.; Tokoro, C.; Tanaka, M.; Motokawa, R.; Shiwaku, H.; Yaita, T. Selective extraction of $\mathrm{Pt}(\mathrm{IV})$ over $\mathrm{Fe}(\mathrm{III})$ from $\mathrm{HCl}$ with an amide-containing tertiary amine compound. Sep. Purif. Technol. 2017, 177, 176-181. [CrossRef]

26. Bell, K.J.; Westra, A.N.; Warr, R.J.; Chartres, J.; Ellis, R.; Tong, C.C.; Blake, A.J.; Tasker, P.A.; Schröder, M. Outer-sphere coordination chemistry: Selective extraction and transport of the $\left[\mathrm{PtCl}_{6}\right]^{2-}$ Anion. Angew. Chem. Int. Ed. 2008, 47, 1745-1748. [CrossRef] [PubMed] 